\title{
Production Rate Regression Model of Railway Construction Project based on Grid
}

\author{
Wenrui Ren ${ }^{1,}$, , Renkui Liu ${ }^{1}$, Futian Wang ${ }^{2}$ and Mengyi Sun ${ }^{1}$ \\ ${ }^{1}$ School of Traffic and Transportation, Beijing Jiaotong University, Beijing 100044, China \\ ${ }^{2}$ State Key Lab of Rail Traffic Control \& Safety, Beijing Jiaotong University, Beijing 100044, China \\ a14120951@bjtu.edu.cn
}

Keywords: Railway construction project, Time-space grid, Production rate regression model.

\begin{abstract}
Project schedule has been regarded as the core work of the project management. Scheduling and using the project schedule scientifically and reasonably is the key to ensure the organization work of construction project orderly. In this paper, the time-location-based division method of influencing factors has been developed according to their time-spatial varying features. The paper has collected the actual construction progress data and taken use of multiple linear regression analysis determining the incidence relation between the production rates and influence factors. Then the regression model with varying production rates based on grids could be developed. Finally, the practical schedule data of railway $\mathrm{Wu}$ Caiwan-Jiang Junmiao sectional subgrade engineering has been utilized to verify the validity of the model.
\end{abstract}

\section{Introduction}

Due to the uncertainties of construction site condition and environment, the construction production rate of construction engineering is usually not fixed. The prediction of construction rate has become a more and more important part when making project schedule. Simon [1] pointed out that System Analysis Method is not suitable for predicting the production rate of earthwork engineering, and he proposed quantifying the impact of each factor by using multiple stepwise regression analysis in 1999. In 2004, Yao [2] pointed out that the inaccuracy of the prediction of construction rate is the main reason to the inaccuracy of duration prediction of CPM. In 2007, based on the historical statistical data and construction experience, $\mathrm{Yi}$ [3] found that the temperature and season, geographical position of the site and the road type are the main factors that influence the production rate.

It can be seen that there is still room for improving the method of prediction of construction production rate, and a scientific method of classification of factors that influence the production rate and a suitable method for predicting the construction rates are needed. This paper propose a timelocation- based division method of influencing factors according to their time-spatial varying features, and develop a regression model with varying production rates based on grids .

\section{Classification of Factors that influence production rates}

\subsection{Factors that influence production rates}

Railway construction progress is affected by many factors because railway construction project has characteristics of long construction duration, continual construction in the wild all year long and so on. The factor of human is the most important interference factor in the railway construction progress control. At the same time, the factor of equipment and materials, money, hydrology, geological and meteorological conditions, social environment should also be analyzed and controlled [4].

In the implementation stage of construction project, $4 M 1 E$ method is well used to identify the factors that influence construction quality [5]. This method is also used in the construction safety management. Based on railway construction characteristic and literature discourse [6-9], the factors that influence construction progress are classified into five categories: Man, Material, Machine, 
Method, and Environment. This paper inductively arranges factors that influence construction progress by $4 M 1 E$ method as figure 1 .

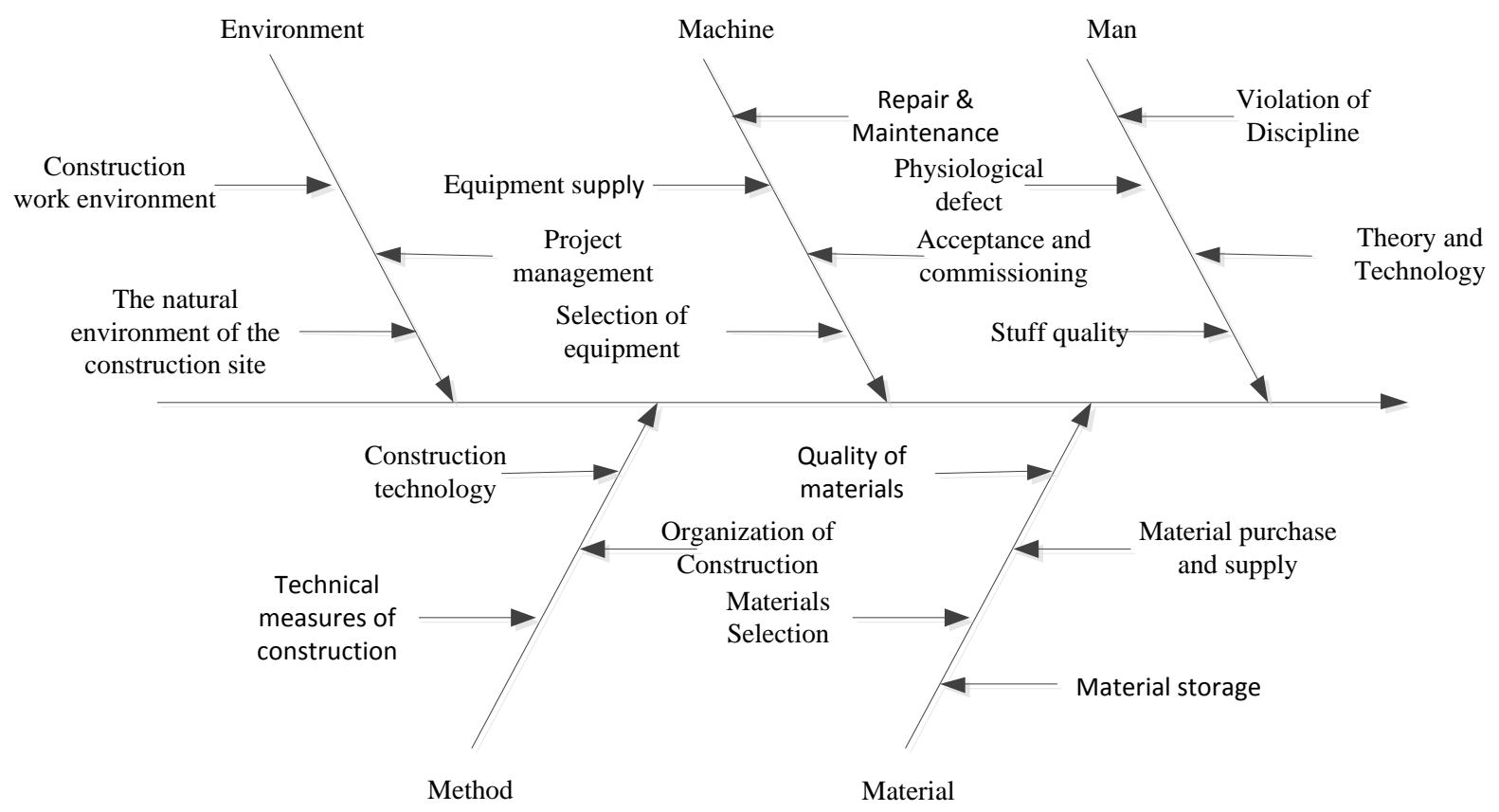

Fig. 1 The main factors affecting the construction progress

\subsection{Classification of Factors}

In the progress of railway construction, the influence factor varies with time, and from position to position. Most influence factors have close association with construction mileage and time, while the factor classification of $4 M 1 E$ method cannot present the time-space characteristic of factors. According to whether factors vary with time and space, influence factors are classified into general factor, time factor, space factor and time-space factor as shown in table 1.

Table 1. The classification of the main factors affecting the railway construction progress

\begin{tabular}{|c|c|c|}
\hline Factor Classification & 4M1E Factor Classification & Factor \\
\hline \multirow{7}{*}{ General } & \multirow{3}{*}{ Human } & Physiological defect \\
\hline & & Stuff quality \\
\hline & & Violation of Discipline \\
\hline & Material & Material quality \\
\hline & Machine & Acceptance and commissioning \\
\hline & Environment & Construction schedule control system \\
\hline & Methhod & Construction technology \\
\hline \multirow{4}{*}{ Time } & Man & Theory and Technology \\
\hline & Machine & Machinery and equipment supply plan \\
\hline & Method & Construction schedule control system \\
\hline & Material & Material purchase and supply plan \\
\hline \multirow[t]{2}{*}{ Space } & \multirow[t]{2}{*}{ Environment } & $\begin{array}{l}\text { The natural environment of the construction } \\
\text { site }\end{array}$ \\
\hline & & Construction work environment \\
\hline \multirow{6}{*}{ Time-Space } & \multirow[t]{2}{*}{ Environment } & $\begin{array}{l}\text { The natural environment of the construction } \\
\text { site }\end{array}$ \\
\hline & & Construction work environment \\
\hline & Machine & Repair \& Maintenance \\
\hline & \multirow{2}{*}{ Method } & Construction technical measures \\
\hline & & Construction site organization and management \\
\hline & Material & Material storage \\
\hline
\end{tabular}




\section{Production rate regression model of railway construction project based on Grid}

Based on multiple regression analysis method, this model establishes relationship between construction activity production rate and the influencing factors. By inputting the statistical data of influence factors, this model can output the possible construction rates that conform to reality.

\subsection{Definition of railway construction project grid}

According to the time-space feature of factors that influence railway construction rates [10], railway construction project grid is proposed in this paper. Railway construction project grid means the discretization of the continuous railway construction line, which is divided into many small construction line sections. Meanwhile, the continuous working time is also divided into many small working time sections. The time-space construction region constructed by the line section and time section is named grid unit, and is given an ID (namely grid code). According to the time-space feature of the railway construction project grid, the grid unit is named $G_{i j}$, in which $i$ represents the column of the gird (the position of construction mileage section) and $j$ means the row of the grid (the position of construction time section).In this way, the time-space position of the grid can be found quickly as figure 2 .

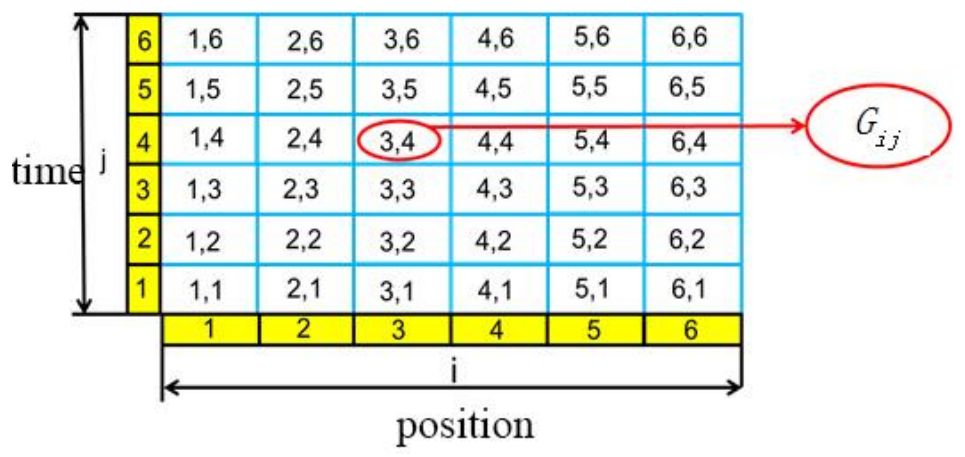

Fig. 2 The railway construction project grid

\subsection{The division of railway construction project grid}

(1) The division of grid length. The railway is band shaped, and the width is fixed normally, so the length of the railway construction project gird should be divided by the length of the railway line. Referring to many rule and explanation of railway construction project, it is believed that $200 \mathrm{~m}$ is a suitable length as unit length of railway construction project grid.

(2) The division of grid time. In implementation stage of the project, the schedule management situation varies. For construction companies, implementation schedule usually uses day or week as time unit. On the other hand, day is the smallest unit in railway construction project scheduling in China. Therefore, day is used in this paper as the time unit of railway construction project grid.

\subsection{Regression model of construction rate and factor}

According to the classification of factors that influence construction rate and research and analysis of relative literatures and historical materials about construction rate prediction, this paper arranges the important influence factors which are usually considered when making construction schedule, and regardless of the change of influence factors in construction progress, as table. To make a better quantify of impact, this paper mainly focuses on the first five factors in the table 2.

In the railway construction production rate regression model, random variable $P R$ represents construction rate of current construction activity, and $\mathrm{k}$ variables $X_{1}, X_{2}, \ldots, X_{k}(k \geq 2)$ represent the factors that influence construction rate in this research. The multiple linear regression model is shown as blow:

$P R=\beta_{0}+\beta_{1} X_{1}+\beta_{2} X_{2}+\cdots+\beta_{k} X_{k}+\varepsilon$

In which, $\beta_{0}, \beta_{1}, \ldots, \beta_{k}$ are $k+1$ unknown parameters, $\beta_{0}$ is regression constant, $\beta_{1}, \beta_{2}, \ldots, \beta_{k}$ are regression factors, and $\varepsilon$ is random deviation. 
Table 2. The important factors affecting construction progress

\begin{tabular}{|c|c|c|c|}
\hline No. & Factor & Description & Source \\
\hline 1 & Weather condition & $\begin{array}{c}\text { Temperature, wind, } \\
\text { precipitation } \\
\text { Time and mileage } \\
\text { section out of work }\end{array}$ & $\begin{array}{c}\text { Construction organization } \\
\text { planninng, construction journal }\end{array}$ \\
\hline 2 & Working window & & $\begin{array}{c}\text { Construction organization } \\
\text { planninng }\end{array}$ \\
\hline 3 & Terrain slope & & $\begin{array}{c}\text { Construction organization } \\
\text { planninng }\end{array}$ \\
\hline 4 & Vacation & & \begin{tabular}{c} 
Construction journal \\
\hline 5
\end{tabular} \\
\hline 6 & Number of workers & & $\begin{array}{c}\text { Construction organization } \\
\text { planninng, Consstruction } \\
\text { drawing }\end{array}$ \\
\hline 7 & Topography & Plain,dessert,etc. & $\begin{array}{c}\text { Construction organization } \\
\text { planninng,site survey }\end{array}$ \\
\hline 8 & Scope of construction land & & $\begin{array}{c}\text { Construction organization } \\
\text { planninng, Consstruction } \\
\text { drawing }\end{array}$ \\
\hline 9 & Urbanization & Population density & $\begin{array}{c}\text { Construction organization } \\
\text { planninng }\end{array}$ \\
\hline 10 & Theory and Technology & & \begin{tabular}{c} 
Experience data \\
\hline
\end{tabular} \\
\hline
\end{tabular}

This paper takes the practical data of two activities of railway Wu Caiwan-Jiang Junmiao sectional subgrade engineering (DK96+000 DK115+300) as the source data to build the regression equation. The data is analyzed and proceeded by Excel and SPSS19.0 to get the regression equation.

Production rate regression model of embankment and bottom layer of foundation bed filling activity

The analysis results show that the production rate and the filling layer are related to the lowest temperature, and the production rate regression equation is show as blow:

$P R_{i j}=165.519-3.251 F L_{i}+0.286 M T_{i j}$

In which, $P R_{i j}$----activity production rate (m/day),

$F L_{i}$----the number of filling layers in working day,

$M T_{i j}$----the lowest temperature in working day $\left({ }^{\circ} \mathrm{C}\right)$.

Production rate regression model of surface layer of foundation bed filling activity

The analysis results show that the production rate is related to the lowest temperature and the maximum wind speed, and the production rate regression equation is show as blow:

$P R_{i j}=193.123-0.545 M W S_{i}+0.332 M T_{i j}$

In which, $P R_{i j}$----activity production rate (m/day),

$M W S_{i j}{ }^{----t h e ~ m a x i m u m ~ w i n d ~ s p e e d ~ i n ~ w o r k i n g ~ d a y ~}(\mathrm{~m} / \mathrm{s})$,

$M T_{i j}$----the lowest temperature in working day $\left({ }^{\circ} \mathrm{C}\right)$.

\subsection{Production rate regression model of railway construction project based on Grid}

Based on the production rate regression equation in section 3.3, taking the arrangement of working time into account, the working day variable can be added into the equation to present if this day is a 
working day or not. Value 1 represents that today is a working day, and value 0 means not, for example, vacation, etc.

According to the time-space feature of factors that influence railway construction rates, corner mark $i$ and $j$ are given to factor variable. Together with the code of time-space grid, a new grid-based production rate regression model is build.

(1) grid-based production rate regression model of embankment and bottom layer of foundation bed filling activity

$$
P R_{i j}=W D_{i j} \times\left(-3.251 F L_{i}+0.286 M T_{i j}+165.519\right)
$$

In which, $P R_{i j}$----activity production rate (m/day),

$W D_{i j}{ }^{----w o r k i n g ~ d a y ~(~} 1$ for positive and 0 for negative),

$F L_{i}$----the number of filling layers in working day,

$M T_{i j}$----the lowest temperature in working $\operatorname{day}\left({ }^{\circ} \mathrm{C}\right)$.

(2) grid-based production rate regression model of surface layer of foundation bed filling activity

$$
P R_{i j}=W D_{i j} \times\left(-0.545 M W S_{i}+0.332 M T_{i j}+193.123\right)
$$

In which, $P R_{i j}$----activity production rate (m/day),

$W D_{i j}$----working day ( 1 for positive and 0 for negative),

$M W S_{i j}$----the maximum wind speed in working day $(\mathrm{m} / \mathrm{s})$,

$M T_{i j}{ }^{----t h e ~ l o w e s t ~ t e m p e r a t u r e ~ i n ~ w o r k i n g ~} \operatorname{day}\left({ }^{\circ} \mathrm{C}\right)$.

\section{Case study}

This paper takes a subgrade engineering of a new-built railway line as example, using production rate regression model to generate project schedule. After that, a comparison between original schedule, real schedule and mode schedule will be made. The original schedule of the construction project is made by the site engineer based on constrains between construction activities and personal construction experience. The comparisons of three schedules of two activities are shown as blow. Embankment and bottom layer of foundation bed filling activity.

Table 3. The time-location information summary table of the three schedules surface layer of foundation bed filling activity

\begin{tabular}{|c|c|c|c|c|}
\hline & Mileage & Original Schedule & Real Schedule & Model Schedule \\
\hline Start Position & SDK1+000 & $2009-03-05$ & $2009-03-05$ & $2009-03-05$ \\
\hline End Position & SDK7+700 & $2009-04-30$ & $2009-05-13$ & $2009-05-09$ \\
\hline Total & $6700 \mathrm{~m}$ & 56 days & 69 days & 65 days \\
\hline
\end{tabular}

Table 4. The time-location information summary table of the three schedules

\begin{tabular}{|c|c|c|c|c|}
\hline & Mileage & Original Schedule & Real Schedule & Model Schedule \\
\hline Start Position & SDK1+000 & $2009-04-10$ & $2009-04-10$ & $2009-04-10$ \\
\hline End Position & SDK7+700 & $2009-05-10$ & $2009-05-20$ & $2009-05-17$ \\
\hline Total & $6700 m$ & 30 days & 40 days & 37 days \\
\hline
\end{tabular}

From table 3 and 4, it can be seen that the duration of model schedule made is closer to the real schedule than the original schedule in both activities. Therefore, the grid based production rate regression model of railway construction project is superior to the original planning method. 


\section{Summary}

Improving the method of prediction of construction production rate is important for construction industry, and a scientific method of classification of factors that influence the production rate and a suitable method for predicting the construction rates are needed. The main research results of this paper include the following points:

(1) Develop a time-location-based division method of influencing factors according to their time-spatial varying features,

(2) Use multiple linear regression analyze the incidence relation between the production rates and influencing,

(3) Develop a regression model with varying production rates based on grids.

Although the theory and method proposed in this paper have advantage in practical application, there are still some shortages in this paper. For example, the factors considered in this paper are not enough, and the regression model is still needed to be improved. All these need further study in the future.

\section{References}

[1] Smith S D. Earthmoving productivity estimation using linear regression techniques. Journal of Construction Engineering and Management. Vol.125 (1999) No. 3, p. 133-141.

[2] Kuo Y. Highway earthwork and pavement production rates for construction time estimation. Doctor degree, University of Texas, American, 2004.

[3] Jiang Y, Wu H B. Production rates of highway construction activities. International Journal of Construction Education and Research. (2007) NO.3, p. 81-98.

[4] Yisheng Liu. Construction project progress plan and control. China Construction Industry Press, 2008.

[5] Lu Zhang. How to make auality control of 4M1E in building construction. Shanxi Construction. Vol. 35 (2009) No.1, p. 238-240.

[6] Xinghuai Li. Safety management of construction working using 4M1E factor. Construction Safety. (2011) No.1, p.7-9.

[7] Hua Yang. Application of 4M1E in construction management. Water Conservancy Construction and Management. (2009) No.11, p.23-29.

[8] Dongjin Li. Quality control progress of construction project. Doctor degree. Xi' an University of Architecture and Technology, China, 2003.

[9] Wei Wang. Research on quality management and control of highway projects. Doctor degree, Central South University, China, 2010.

[10] Genmou Jiang. Linear project schedules and resource allocation optimization. Doctor degree, Nanchang University, China, 2008. 